\title{
Biochemical composition of different body parts of Gafrarium tumidum (Roding, 1798) from Mandapam, South East Coast of India
}

\author{
A. Babu ${ }^{1 *}$, V. Venkatesan ${ }^{2}$ and S. Rajagopal ${ }^{1}$ \\ ${ }^{1}$ CAS in Marine Biology, Faculty of Marine Sciences, Annamalai University, Parangipettai 608 502, India. \\ ${ }^{2}$ Regional Centre of Central Marine Fisheries Research Institute, Mandapam Camp 623 520, India.
}

Accepted 20 May, 2011

\begin{abstract}
Due to its abundance in various areas along the Mandapam coast (latitude $9^{\circ} 17^{\prime \prime} \mathrm{N}$; longitude $79^{\circ} 11^{\prime \prime} \mathrm{E}$ ), Southeast coast of India, the commonly occurring intertidal bivalve Gafrarium tumidum was selected for this study to investigate its nutritive value. Tissues of different body parts such as mantle, viscera and foot were analyzed. Biochemical constituents like protein, carbohydrate and fat were estimated in different body parts and the percentage of protein was $61.74 \%$, carbohydrate $32.64 \%$ and lipid $14.37 \%$. The fatty acids of bivalve were analyzed by gas chromatography/mass spectrometry. In the fatty acids, polyunsaturated fatty acids (PUFA) were found to be dominant, contributing $6.99 \%(2.34,2.67$ and $1.98 \%$ mantle, viscera and foot, respectively), whereas saturated fatty acids (SFA) contributed $5.19 \%(1.70$, 1.94 and $1.55 \%)$ followed by monounsaturated fatty acids (MUFA) which contributed $2.75 \%(0.920 .93$ $0.90 \%)$. Stearic $(0.81 \%)$ and palmitic acids $(0.71 \%)$ were the dominant saturated fatty acid in viscera and oleic acid $(0.93 \%)$ was the monounsaturated fatty acid found in the viscera. Linoleic $(1.38 \%)$ and $\alpha-$ linolenic acids (1.07\%) were the dominant polyunsaturated fatty acid in viscera. The total amino acid detected was found to be $42.97 \%$, among them the essential amino acids (EAA) was $20.77 \%$ and the non essential amino acids (NEAA) present was found to be $22.2 \%$. The results of this study revealed that phenylalanine (1.19\%) and methionine (1.04\%) in EAA and alanine $(1.10 \%)$ and glutamic acid $(1.10 \%)$ in NEAA were the major constituents. It could also be added that the composition of marine bivalves is a nutritional assurance to millions of malnourished people.
\end{abstract}

Key words: Mandapam, bivalve, Gafrarium tumidum, fatty acid, amino acid, biochemical composition,

\section{INTRODUCTION}

Molluscs are delicious and protein rich food among the sea foods (Jagadis, 2005). The bivalves in the coastline could form an important source of food, raw material for village industries, indigenous medicine, etc, and it is widely used as a cheaper food source for coastal area people. Shellfish such as mussel, clam contains approximately 20 to $28 \%$ calories of fat. Shellfish also provide high quality protein with all the dietary essential amino acids for maintenance and growth of thtabe human body. For this reason, shellfish should be considered a low-fat, high-protein food that can be included in a low-fat diet (King et al., 1990).

\footnotetext{
*Corresponding author. E-mail: molluscbabu@gmail.com.
}

Fatty acids in marine invertebrates are studied in many habitats because of their significance in human life (Ackman, 2000). Molluscs have a great importance because of their fatty acid components and their variability in different areas. The polyunsaturated fatty acids (PUFA) have been recognized as effective factors in human health and nutrition, especially for cardiovascular diseases (Bruckner, 1992). The quality of protein is usually assessed by its amino acid composition. The amino acid composition in turn is helpful in assessing the nutritive value of an organism. Gafrarium tumidum is a facultatively mobile infaunal suspension feeder. Due to the importance and abundance of the commercial bivalve species, G. tumidum commonly occur in intertidal areas of Indian coasts; this study investigated the nutritive value of $G$. tumidum using 
gas chromatography/mass spectrometry.

\section{MATERIALS AND METHODS}

Samples of the bivalves, G. tumidum were collected during low tide in September, 2009 to March 2010 in Mandapam (latitude $9^{\circ} 17^{\prime \prime} \mathrm{N}$; longitude $79^{\circ}$. 11"E) waters in Gulf of Mannar, Tamil Nadu, Southeast coast of India. The specimens (20 animals) were brought to the laboratory, cleaned with brush, and immediately dissected. Proximate composition of $G$. tumidum were analysed in triplicate for protein, carbohydrate and lipid.

The Folin-Ciocalteu phenol method of Lowry et al. (1951) was adopted for the estimation of total proteins in the tissue. The dry tissue sample weighing $10 \mathrm{mg}$ was thoroughly homogenized with 1 $\mathrm{ml}$ of deproteinizing agent (10\% TCA) by keeping the tubes in ice. All samples were centrifuged for $20 \mathrm{~min}$ at $3000 \mathrm{rpm}$. The precipitate obtained was used for protein estimation. The precipitate was dissolved in $2 \mathrm{ml} 1 \mathrm{~N} \mathrm{NaOH}$ and to $1 \mathrm{ml}$ of this solution, freshly prepared $5 \mathrm{ml}$ alkaline reagent was added. This was kept at room temperature for $10 \mathrm{~min}$, after which $0.5 \mathrm{ml}$ of $1 \mathrm{~N}$ Folin-Ciocalteu reagent was added and mixed rapidly. A standard stock solution was prepared using bovine serum albumin crystals at a concentration of $25 \mathrm{mg} / 5 \mathrm{ml} \mathrm{NaOH}$. Different dilutions in the range of 0.25 to $2.5 \mathrm{mg} / \mathrm{ml}$ were prepared from this stock solution, the alkaline reagent and Folin-Phenol reagent was added as in the case of tissue samples. A blank was prepared with $1 \mathrm{ml} 1 \mathrm{~N} \mathrm{NaOH}$ and treated the same way as earlier mentioned. All the test tubes were kept for $30 \mathrm{~min}$ at room temperature, the blue colour developed, and the O.D was evaluated against the blank at 660 $\mathrm{nm}$ :

$$
\% \text { composition of protein }=\frac{\text { Standard value } \times \text { OD of sample }}{\text { Weight of tissue }} \times 100
$$

For the estimation of total carbohydrate content, the procedure of Dubois et al. (1956) using phenol-sulphuric acid was followed.

About $5 \mathrm{mg}$ of oven-dried tissue was taken for carbohydrate analysis. The tissue was taken in a test tube and $1 \mathrm{ml}$ of phenol $(5 \%)$ and $5 \mathrm{ml}$ concentrate $\mathrm{H}_{2} \mathrm{SO}_{4}$ were added in quick succession. The tubes were kept for $30 \mathrm{~min}$ at $30^{\circ} \mathrm{C}$ and the optical density (OD) of the colored developed was measured at $490 \mathrm{~nm}$ against the blank. D-glucose was used as a standard and it had an optical density value of 0.1 carbohydrate as calculated by using the formula:

$$
\text { \%composition of carbohydrate }=\frac{\text { Standard value } \times \text { OD of sample }}{\text { Weight of tissue }} \times 100
$$

The chloroform-methanol extraction procedure of Folch et al. (1956) was used for extracting lipid from the various body parts.

The lipid content was estimated gravimetrically by following Folch et al. (1956) method. The lipid was extracted from $500 \mathrm{mg}$ of powdered oven-dried tissue with $5 \mathrm{ml}$ of cholorofom : methanol (2:1) mixture added. The mixture was filtered by a micro filter. This extract was taken in a pre weighed beaker and oven dried. Beaker was reweighed with lipid. The difference in weight was taken as total lipid content and the percentage was calculated as follows:

$$
\% \text { composition of lipid }=\frac{\text { Weight of lipid }}{\text { Weight of tissue }} \times 100
$$

Analysis of fatty acids (Kashiwagi et al., 1997)

Preparation of samples was oven dried at $70^{\circ} \mathrm{C}$ for $24 \mathrm{~h}$ until no more weight reduction was observed. After that the samples were grounded finely with pestle and mortar. To the 100 to $200 \mathrm{mg}$ of finely ground tissue samples, 1:1 ratio of chloroform : methanol (2 $\mathrm{ml}$ ) was added and kept for $30 \mathrm{~s}$. The residual matter was removed by filtering through Whatman No.1 filter paper $(125 \mathrm{~mm})$. This was washed with $1 \mathrm{ml}$ of chloroform : methanol (2:1 vol) to remove the inorganic substances from the combined extract by partition and treated with chloroform : methanol : water $(8: 4: 3)$ where the lower phase evaporated to dryness. The dried matter was put in a sealed test tube with $3 \%$ methanolic $\mathrm{HCL}$ at $80^{\circ} \mathrm{C}$ for $18 \mathrm{~h}$. To this, $2 \mathrm{ml}$ of hexane was added to extract the fatty acid ethyl esters obtained from methanol phase in hexane. Upper $1 \mathrm{ml}$ of the hexane phase was collected in a micro vial. The residual fraction was dissolved in $10: 1$ of ethyl acetate and 1:1 aliquot was injected into a gas chromatograph (Agilent 6890, 1997) equipped with flame identification detector and column HP ULTRA - $2(25 \mathrm{~m}, 0.2 \mathrm{~mm}$ ID).

\section{Estimation of amino acid}

The collected specimens were dried at $60^{\circ} \mathrm{C}$ for $24 \mathrm{~h}$ in an oven and they were packed in airtight polyethylene covers and kept in desiccators. The oven-dried samples were finely grounded before estimating amino acid profile. Amino acids were estimated in HPLC - Lachrom e merck in SPD- 10A VP Detector.

\section{RESULTS}

The percentage composition of protein values were 20.56, 24.82 and $16.36 \%$ in mantle, viscera and foot, respectively. The carbohydrate concentration was 9.02 , 13.53 and $10.09 \%$ in mantle, viscera and foot, respectively. The lipid content observed in mantle was $4.12 \%$, viscera $7.26 \%$ and foot $2.99 \%$. The maximum observed was in viscera: $24.82,13.53$ and $7.26 \%$ protein, carbohydrate and lipid respectively (Table 1 ).

The fatty acid composition of $G$. tumidum was analyzed by combined GC-MS technique, and the result showed the presence of 7 fatty acids. Among them, 3 were saturated, 1 was monounsaturated and 3 were polyunsaturated fatty acids. While the fatty acid composition of the mantle, viscera and foot of $G$. tumidum displayed similar components, their distribution varied among the three organs investigated.

In this study, the polyunsaturated fatty acids (PUFA) $(2.34 \%)$ were the dominant fatty acids. The saturated fatty acid was the next most common (1.69\%). The monounsaturated fatty acids (MUFA) occupying the third position contributed $0.92 \%$ (Table 2 ).

Amino acid analysis refers to the methodology used to determine the amino acid composition or content of proteins and peptides. The total amino acid content of $G$. tumidum was $42.97 \%$. The essential amino acids (EAA) were $20.77 \%$ and non-essential amino acids (NEAA) were $22.20 \%$. Among them, phenylalanine 1.10, 1.1, 9 $1.00 \%$ and methionine $1.02,1.04$ and $1.00 \%$ in mantle, viscera and foot, respectively forms the major essential 
Table 1. Proximate composition of G. tumidum.

\begin{tabular}{lccc}
\hline Proximate composition & Protein (\%) & Carbohydrate (\%) & Fat (\%) \\
\hline Mantle & 20.56 & 9.02 & 4.12 \\
Viscera & 24.82 & 13.53 & 7.26 \\
Foot & 16.36 & 10.09 & 2.99 \\
Total & 61.74 & 32.64 & 14.37 \\
\hline
\end{tabular}

Table 2. Composition of fatty acids in G. tumidum.

\begin{tabular}{|c|c|c|c|c|}
\hline Saturated fatty acid (SFA) & Nomenclature & Mantle (\%) & Viscera (\%) & Foot (\%) \\
\hline Palmitic & C16:0 & 0.57 & 0.71 & 0.46 \\
\hline Margaric & $\mathrm{C} 17: 0$ & 0.32 & 0.42 & 0.29 \\
\hline Stearic & C18:0 & 0.81 & 0.81 & 0.80 \\
\hline Total & & 1.70 & 1.94 & 1.55 \\
\hline \multicolumn{5}{|c|}{ Monounsaturated fatty acids (MUFA) } \\
\hline Oleic & C18:1 $\omega-9$ & 0.92 & 0.93 & 0.90 \\
\hline Total & & 0.92 & 0.93 & 0.90 \\
\hline \multicolumn{5}{|c|}{ Polyunsaturated fatty acids (PUFA) } \\
\hline Linoleic & $\mathrm{C} 18: 2 \omega-6$ & 1.30 & 1.38 & 1.02 \\
\hline$\alpha$-Linolenic & C18:3 $\omega-3$ & 0.93 & 1.07 & 0.86 \\
\hline Morotic & C18:4 & 0.11 & 0.22 & 0.10 \\
\hline Total & & 2.34 & 2.67 & 1.98 \\
\hline
\end{tabular}

Table 3. Essential amino acid composition of G. tumidum (g amino acid/100 g protein).

\begin{tabular}{lccc}
\hline Essential amino acid & Mantle (\%) & Viscera (\%) & Foot (\%) \\
\hline Phenylalanine & 1.10 & 1.19 & 1.00 \\
Threonine & 0.87 & 0.92 & 0.75 \\
Valine & 0.31 & 0.50 & 0.30 \\
Histidine & 0.56 & 0.67 & 0.47 \\
Isoleucine & 0.91 & 1.08 & 0.90 \\
Methionine & 1.02 & 1.04 & 1.00 \\
Leucine & 0.86 & 0.91 & 0.76 \\
Lysine & 0.12 & 0.34 & 0.11 \\
Proline & 0.21 & 0.31 & 0.11 \\
Tryptophan & 0.79 & 0.98 & 0.68 \\
Total & 6.75 & 7.94 & 6.08 \\
\hline
\end{tabular}

amino acids (Table 3). Alanine 1.09, 1.10, 1.02\% and glutamic acid $0.99,1.08,0.86 \%$ contributed as the major non-essential amino acids. Lysine in essential amino acids and serine in non-essential amino acids showed the lowest concentration (Table 4).

\section{DISCUSSION}

Biochemical constituents like protein, carbohydrate and lipid were estimated in the different body components of the intertidal bivalve $G$. tumidum and among the body fractions, viscera recorded the highest fatty acid amino acid as well as high percentage of biochemical constituents. Investigation on biochemical composition in different parts of an animal would be more informative than estimation in the entire body for studies (Giese, 1969). Biochemical compositions in different body fraction were mainly influenced by reproductive cycle and secondarily by food availability. Accumulation of protein, 
Table 4. Non essential amino acid composition of $\mathrm{G}$. tumidum (g amino acid/100 $\mathrm{g}$ protein).

\begin{tabular}{lccc}
\hline Non essential amino acid & Mantle (\%) & Viscera (\%) & Foot (\%) \\
\hline Alanine & 1.09 & 1.10 & 1.02 \\
Arginine & 0.97 & 1.07 & 0.85 \\
Asparagine & 0.31 & 0.51 & 0.30 \\
Aspartic acid & 0.71 & 0.71 & 0.69 \\
Cystine & 0.91 & 0.97 & 0.86 \\
Glutamic acid & 0.99 & 1.08 & 0.86 \\
Glutamine & 0.41 & 0.61 & 0.37 \\
Glycine & 0.91 & 1.10 & 0.88 \\
Serine & 0.11 & 0.34 & 0.10 \\
Tyrosine & 0.78 & 0.91 & 0.68 \\
Total & 7.19 & 8.40 & 6.61 \\
\hline
\end{tabular}

carbohydrate and lipid will be high during proliferation of gonads (George, 1980). Percentage of these constituents will increase during maturation of gonads (Ansell, 1974). Among the three body fractions, viscera portion recoded high values of protein, carbohydrate and lipid. The digestive gland acts as a storage site in most of the bivalves (George, 1980). Variations in the biochemical constituents in viscera indicate that this organ acts as probable storage site in G. tumidum and the adductor muscles to a lesser extent. Generally, in bivalves, the bivalve storage sites vary.

The biochemical compositions of G. tumidum tissue are similar to those of other marine bivalves, such as oyster and scallops, which typically have high protein content and low levels of fat and cholesterol. The fat and cholesterol content of number of bivalves including oyster, scallops, mussels and cockles, ranged between 1.3 and $2.3 \%$ and 0.33 and $0.59 \%$, respectively (Pearson, 1977).

The seasonal variation in biochemical constituents of different body components of Meretrix meretrix were studied by Jayabal and Kalyani (1987), the results showed $24.82 \%$ protein, $13.53 \%$ carbohydrate and $7.26 \%$ fat. The results of these species showed the same trend. Biochemical constituents of many species have been analyzed by Rajan et al. (1990) and Jagadis (2005).

Fatty acids are the fundamental structural components of practically all forms of lipids. Fatty acid profiles of other molluscs are usually dominated by PUFA and the present study also revealed the same where, maximum PUFA was present in G. tumidum. Studies have found evidence that $\alpha$-linolenic acid is related to lower risk of cardiovascular disease. Dietary $\alpha$-linolenic acid has been assessed for its role in cardiovascular health. The weight of the evidence favors recommendations for modest dietary consumption of $\alpha$-linolenic acid ( 2 to $3 \mathrm{~g}$ per day) for the primary and secondary prevention of coronary heart disease.

Linoleic acid is a polyunsaturated omega- 6 fatty acid; it is called $18: 2(n-6)$. Linoleic acid is an essential fatty acid that must be consumed for proper health. Lack of linoleic acid and other omega- 6 fatty acids in the diet causes dry hair, hair loss and poor wound healing. Linoleic acid is used in making soaps, emulsifiers and quick-drying oils. Linoleic acid has become increasingly popular in the beauty products industry because of its beneficial properties on the skin. Research points to linoleic acid's anti-inflammatory, acne reductive and moisture retentive properties when applied topically on the skin.

a-Linolenic acid is an organic compound and it is a polyunsaturated n-3 (omega-3) fatty acid. Eicosapentaenoic acid (EPA; 20:5, $n-3$ ) and docosahexaenoic acid (DHA; 22:6, $n-3)$ are readily available and play a vital role in many metabolic processes. In this study, their health benefits and their food sources related to $n-3$ PUFA, was increased. Murphy et al. (2003) observed that the freeze dried and frozen samples of green lipped mussels of Perna canaliculus, among the 30 individual fatty acids, polyunsaturated fatty acids were found to be dominant (40 to $41 \%$ of total PUFA). The majority of marine species are rich sources of long chain PUFA, particularly 22:6 n-3 and 20:5 n-3. The New Zealand mollusc Mytilus canaliculus for instance contains a similar profile with the mussels which are rich in 22:6 n-3 and 20:5 n-3.

Shanmugam et al. (2007) recorded 36 individual fatty acids that were identified. Among them, the saturated fatty acids were the dominant fatty acids $(35.28 \%)$ and most of which were 18:0 (15.68\%) and 14:0 (7.15\%). The monounsaturated fatty acids (MUFA) were the next most common fatty acids $(26.57 \%)$ with the higher levels of 16:1w7c (12.71\%) and 18:1w9c (11.18\%). The PUFA occupying the third position contributed $11.72 \%$ of total fatty acids, represented by $20: 4(6.75 \%)$ and $18: 2$ $(2.41 \%)$ together accounted for about $90 \%$ of the PUFA. At the same time, the omega- 6 and omega- 3 fatty acids accounted for $10.74 \%$ and $0.48 \%$ of the total PUFA. But in this study, only 7 fatty acids were recorded. Among 
them, 3 were saturated fatty acid, 1 was unsaturated fatty acid and 3 were polyunsaturated fatty acids. Kalyani (1991) reported that three species of bivalve mollusks Amussium pleuronectes (Linnaeus) Meretrix meretrix (Linnaeus) and Katelysia opima (Gmelin) wereanalysed for free amino acid and protein amino acid. Among the free amino acids, alanine, glutamic acid, glycine, proline, aspartic acid, phenylaline and threonine showed high concentrations. In this study, the same results of phenylalanine, methionine, alanine and glutamic acid were revealed.

Ajaya (2002) observed amino acid content in the bivalve molluscs Perna virdis, Crassostrea madrasensis and Meretrix casta. A total of 18 amino acids were recorded. The total amino acid in the $P$. virdis was $95.76 \%$, among them essential amino acid was $47.28 \%$. In C. madrasensis, total amino acid was $98.4 \%$, among them essential amino acid was $54.52 \%$, while the least amount found to be $65.17 \%$ was observed only in $M$. casta, among which essential amino acid was $38.17 \%$. In this study, the total amino acid content of G. tumidum was $42.97 \%$. The essential amino acids (EAA) were $20.77 \%$ and non-essential amino acids (NEAA) were $22.20 \%$. Among them, phenylalanine was $1.10,1.19$, $1.00 \%$ and methionine was $1.02,1.04$ and $1.00 \%$ in mantle, viscera and foot, respectively which forms the major essential amino acids. Alanine 1.09, 1.10, 1.02\% and glutamic acid $0.99,1.08,0.86 \%$ contributed as major non-essential amino acids. Lysine in essential amino acids and serine in non-essential amino acids showed the lowest concentration.

Babu et al. (2009) estimated a total of 19 amino acids in the protein of Bursa spinosa (96.8\%). Among them, the essential amino acids $50.1 \%$, non-essential amino acids $46.79 \%$ and unidentified amino acids $3.2 \%$ were found to be present. Methionine $14.54 \%$, threonine $11.21 \%$ and leucine $10.78 \%$ form the major essential amino acids. Glutamine $10.87 \%$, glutamic acid $10.85 \%$ and arginine $10.66 \%$ contributed as the major non-essential amino acids. Valine and phenylalanine showed the lowest concentration of essential amino acids. Alanine showed the lowest concentration among the non-essential amino acids. This study showed that phenylalanine 1.10, 1.19 and $1.00 \%$ and methionine $1.0,21.04$ and $1.00 \%$ in mantle, viscera and foot, respectively forms the major essential amino acids. Alanine 1.09, 1.10 and $1.02 \%$ and glutamic acid $0.99,1.08$ and 0.865 contributed as the major non-essential amino acids. In neuroscience, glutamate is an important neurotransmitter which plays a key role in long-term potentiation and is important for learning and memory (Sapolsky, 2005)

\section{ACKNOWLEDGEMENTS}

The authors are thankful to the Dean, CAS in Marine biology, Faculty of Marine Sciences, Annamalai
University for providing the necessary facilities, and Ministry of Environment and Forest for financial support.

\section{REFERENCES}

Ackman RG (2000). Fatty Acids in Fish and Shellfish. In: Fatty acids in foods and their health implications, Chow CK (Ed.). M. Dekker, Inc., CRC Press, New York and Basel, ISBN: 9780849372612, pp. 153172.

Agilent 6890 (1997). Plus series gas chromatograph system, Br. J. Obstet. Gynaecol., 104: 251-255.

Ajaya BD (2002). Nutritional evaluation of molluscan seafood. Ph.D. Thesis, Annamalai University, India. p. 129

Ansell AD (1974) seasonal changes in biochemical composition of the bivalve Chlamys septemradiata from the Clyde sea area. Marine Biol., 25: 85-99.

Babu A, Kesavan K, Annadurai D, Rajagopal S (2009) Bursa spinosa A Mesogastropod fit for human consumption. Advance J. Food Sci. Technol., Maxwell Scientific Organization, pp. 1-5.

Bruckner G (1992). Fatty acids and cardiovascular diseases. In: Chow CK, editor. Fatty acids in foods and their health implications. New York: Marcel Dekker, pp. 735-752.

Folch J, Lees M, Solane Stanley GH (1956). A simple method for the isolation and purification of total lipid from animal tissues. J. Biol. Chem., 826: 497-509.

George John (1980). Studies on Anadra rhombea (Born) from PortoNovo coastal waters. Ph.D., thesis. Annamalai University, p. 190.

Giese AC (1969). A new aproach to the biochemical composition of the mollusk body. Oceanography Marine Biological Annu. Rev., 7: 115129.

Jagadis I (2005). Biology of an intertidal clam Gafrarium tumidum (Roding) from south east coast of India. Ph.D., thesis, Annamalai University, p. 155.

Jayabal R, Kalyani M (1987) Seasonal variation in biochemical constituents of the different body components of Meretrix meretrix $(\mathrm{L})$ Mahasagar- Bull. Natl. Institute Oceanography, 20(1): 65-69.

Kashiwagi T, Meyer Rochow VB, Nishimura K, Eguchi F (1997). Analysis of fatty acids by G.C. J. Comp. Physiol., B. 167: 1-8.

King I, Childs MT, Dorsett C, Ostrander JG, Monsen ER (1990). Shellfish: proximate composition, minerals, fatty acids, and sterols. J Am. Dietetic Assos., 90: 677-685.

Lowry OH, Rosebrough NJ, Farr AL, Randall RJ (1951). Protein measurement with the tolin phenol reagent. J. Biol. Chem., 193: 265273.

Murphy KJ, Mooney BD, Mann NJ, Nichols PD, Sinclair AJ (2002). Lipid, fatty acid and sterol composition of New Zealand green lipped mussel (Perna canaliculus) and tasmanian blue mussel (Mytilus edulis). Lipids, 37: 587-595.

Murphy KJ, Mann NJ, Sinclair AJ (2003). Fatty acid and sterol composition of frozen and freeze-dried New Zealand green lipped mussel (Perna canaliculus) from three sites in New Zealand. Asia Pacific J. Clin. Nutr., 12(1): 50-60.

Pearson JA (1977). Cholesterol and fatty acids in Australian seafoods. CSIRO Food Res. Quartly, 37: 33-39.

Rajan A, Shanthi B, Kalyani M (1990). Seasonal variation in tissue weight and biochemical composition of different soft body parts of mature Sunetta scipta (Linnaeus) in relation to ecology and reproduction. Environ. Concern Tissue Injury, pp. 107-116.

Sapolsky R (2005). Biology and human behavior: The neurological origins of individuality, 2nd edition. The Teaching Company, Guide Book, pp. $19-20$. 